\title{
Trichloroethylene adsorption extraction under kinetic conditions by carbon materials in the processes of water treatment of food production
}

\author{
Alena Gorelkina ${ }^{1}$, Evgeniy Neverov ${ }^{1,{ }^{*}}$, Irina Timoshchuk $^{1}$, Olga Altshuler ${ }^{1}$ and Elena \\ Ostapova $^{1}$
}

${ }^{1}$ Kemerovo State University, Krasnaya Street, 6, 650000 Kemerovo, Russia

\begin{abstract}
The high level of environmental pollution currently represent a great danger to ecosystems and human health, since a significant part of the generated industrial wastewater is discharged into reservoirs either insufficiently treated or without treatment. In order to reduce the organic substances concentration in the discharged effluents, the use of carbon sorbents is promising. The sorption process requires a comprehensive study, including the process statics, kinetics and dynamics which allows us to establish the features and extraction mechanism. In this paper a model of the studied sorbents granules structure is determined, the mass transfer mechanism in the adaptive control systems is a trichloroethylene (trilene) aqua solution is established, the external mass transfer coefficients which is necessary for engineering calculations are determined. The research results scientific significance lies in the development of the organic substances adsorption theory on the example of trilen by carbon sorbents that differ in the surface structure and properties. The practical significance lies in obtaining kinetic data which is necessary for calculating the wastewater treatment process technological parameters.
\end{abstract}

\section{Introduction}

Degradation of water bodies as a result of anthropogenic load on them and the main factor is the discharge of effluents into water bodies with a significant excess of polluting components. Decrease in ecological functions is also the result of long-term pollution by sewage, which affects not only the state of the reservoir, but also human health, since water bodies are often used as sources of household drinking water supply.

Trilene is dangerous for aquatic organisms and can cause significant changes in the ecosystem. The maximum permissible concentration of trichloroethylene in the water bodies water for economic and drinking and cultural and household water use is 0.005 $\mathrm{mg} / \mathrm{dm} 3$ in accordance with Sanitary Regulations and Norms 1.2.3685-21 "Hygienic

\footnotetext{
* Corresponding author: neverov42@mail.ru
} 
standards and requirements for ensuring the safety and (or) harmlessness of environmental factors for humans".

The compounds negative influence related to trihalomethanes dictates the need to extract trichloroethylene from wastewater for this purpose the adsorption methods using carbon materials use is promising. The sorption equipment development, the technologically effective sorbing material selection requires a comprehensive adsorption study including the process statics, kinetics and dynamics which allows us to establish the extraction features and mechanism.

The trilene sorption under static conditions from aqueous solutions by various sorption materials is presented in paper 6 .

The process of extracting trichloroethylene from the "active carbon-aqueous solution" system is determined by the chemical properties of the extracted component and is difficult to determine the adsorption mechanism. To obtain reliable information about the extraction mechanism under kinetic conditions, a conceptual approach is needed that will allow us to assess the adequacy of existing models and, when comparing theoretical and experimentally obtained data, determine the possibility of using a particular model to characterize the adsorption process under kinetic conditions. This stage is necessary in the comprehensive study of the adsorption process and, subsequently, the rational choice of purification modes based on adsorption extraction.

The study aim was to establish with the help of various models which are describing the sorption extraction kinetics, the mass transfer mechanism and the calculation of mass transfer coefficients necessary for performing engineering calculations.

\section{Materials and methods}

The research objects in this paper are sorbents of the following brands AG-OV-1, KAU, KsAU, Purolat-Standard, their main characteristics are presented in Table 1.

The extraction of trilene was carried out in accordance with the limited volume method. The determination of the content of trilene was carried out according to the method in accordance with GOST R31951-2012. [7]. Pseudo-first-order and pseudo-second-order models were used to model the kinetics of trichloroethylene adsorption on AU.

Table 1. Carbon sorbent specifications

\begin{tabular}{|c|c|c|c|c|}
\hline Brand $A U$ & AG-OB-1 & KAU & KsAU & $\begin{array}{l}\text { Purolat- } \\
\text { Standart }\end{array}$ \\
\hline Manufacturer & $\begin{array}{l}\text { JSC "Sorbent", } \\
\text { Perm }\end{array}$ & $\begin{array}{l}\text { JSC "Sorbent", } \\
\text { Perm }\end{array}$ & $\begin{array}{l}\text { "Eurocarb", } \\
\text { Great Britain }\end{array}$ & $\begin{array}{c}\text { JSC } \\
\text { "Synthesis", } \\
\text { Rostov-on- } \\
\text { Don }\end{array}$ \\
\hline Raw material & $\begin{array}{c}\text { Coal of rank } \\
\text { KS, wood } \\
\text { chemical and } \\
\text { coke chemical } \\
\text { resin } \\
\end{array}$ & Apricot seed shells & Coconut shells & $\begin{array}{l}\text { anthracitic } \\
\text { coal }\end{array}$ \\
\hline Graining (shape) & $\begin{array}{l}\text { Granular } \\
\text { cylinder }\end{array}$ & $\begin{array}{l}\text { granulated, } \\
\text { unequal }\end{array}$ & $\begin{array}{c}\text { granulated, } \\
\text { unequal }\end{array}$ & $\begin{array}{c}\text { granulated, } \\
\text { unequal }\end{array}$ \\
\hline $\begin{array}{c}\text { Carbonation and } \\
\text { activation }\end{array}$ & $\begin{array}{c}\text { Double-stage, } \\
\text { gas-vapor }\end{array}$ & $\begin{array}{c}\text { Double-stage, } \\
\text { gas-vapor }\end{array}$ & $\begin{array}{c}\text { Double-stage, } \\
\text { gas-vapor }\end{array}$ & $\begin{array}{l}\text { Single-stage, } \\
\text { gas-vapor }\end{array}$ \\
\hline Particle size, $\mathrm{mm}$ & $1-5$ & & $1,5-3$ & $0.1-3$ \\
\hline Bulk density, $\mathrm{g} / \mathrm{cm}^{3}$ & 0.52 & 0.417 & 0.49 & 0.68 \\
\hline toughness, \% & 70 & 90 & 97 & $70-80$ \\
\hline
\end{tabular}


Table 1. Continued

\begin{tabular}{|c|c|c|c|c|}
\hline $\begin{array}{c}\text { Specific pore } \\
\text { surface area }\left(S_{B E T}\right), \\
m^{2} / g\end{array}$ & 682 & 1419 & 1512 & 311 \\
\hline $\begin{array}{c}\text { Total pore volume } \\
\text { by water, } \mathrm{cm}^{3} / \mathrm{g}\end{array}$ & 1.03 & 0.97 & 0,951 & 0,500 \\
\hline $\begin{array}{c}\text { Pore volume, } \mathrm{cm}^{3} / \mathrm{g}: \\
\text { micro- }\end{array}$ & 0.22 & 0.31 & 0,622 & 0,070 \\
\hline meso- & 0.24 & 0.66 & 0,110 & 0,000 \\
\hline macro- & 0.57 & - & 0,219 & 0,430 \\
\hline
\end{tabular}

The pseudo-first order equation is widely used to describe the pollutants adsorption rate from aqueous solutions [8]. In linear form this equation looks like this:

$$
\ln \left(a_{e}-a\right)=\ln a_{e}-k_{1} t
$$

where $\mathrm{k}_{1}$ - pseudo-first-order velocity constant, $\min ^{-1}$.

This equation describes the film diffusion cases that controls the rate of adsorption during the first few minutes in mixing experiments [9]. The pseudo-second-order equation [10] is widely used to describe the kinetic laws of adsorption. In the integrated form this equation can be represented as follows [10]:

$$
t / a=1 /\left(k_{2} \cdot a_{e}{ }^{2}+t / a_{e}\right)
$$

where $\mathrm{k}_{2}$ - the pseudo-second order adsorption rate constant, $\mathrm{g} \mathrm{mg}^{-1} \mathrm{~min}^{-1 / 2}$.

In practice, the applicability of a particular mathematical model is possible using a graphical representation by the method of data linearization, and the overlap of experimental data and those obtained using a particular model shows compatibility. Obtaining the determination coefficients tending to unity demonstrates the applicability of the selected model. When choosing a model for describing the process of extracting contaminants under kinetic conditions, it is necessary to have information on the grain structure, for carbon sorbents there are two models of quasi-homogeneous or biporous.

"If an adsorbent grain is considered as a system formed by a disorderly interweaving of micro-and meso-pores in which it is impossible to distinguish between areas with only or predominantly meso-pores and areas containing only micro-pores then such a grain can be attributed to a quasi-homogeneous model." [11;12]

The difference between the biporous model and the quasi-homogeneous one is in the delimitation of the space inside the grain, which determines the order of movement of the extracted components through the porous structure.

Matusovsky R. M. [11] developed a theory of intra-diffusion adsorption kinetics, to assess the possibility of its use in describing the process of trilene extraction under kinetic conditions, a theoretical kinetic equation was obtained that reflects the dependence of the indicator $\gamma$ (defined as the ratio of the adsorption value at a time to the value of equilibrium adsorption $(\mathrm{at} / \mathrm{ap}=\gamma)$ ) from the indicator of the proportional time of the process $\mathrm{T}$.

where $\beta_{\text {п }}$ - external mass transfer coefficient;

$$
\mathrm{T}=\mathrm{A} \beta_{\mathrm{II}} \mathrm{t}, \quad \mathrm{A}=\left(\mathrm{V}_{3} / \mathrm{V}_{\mathrm{p}}+\mathrm{k}_{1}\right)
$$

$\mathrm{V} 3$ - the adsorbent mass total volume, $\mathrm{cm} 3$;

$\mathrm{Vp}$ - the solution volume in contact with the adsorbent;

$\mathrm{k}_{1}$ - constant $\mathrm{k}_{1}=1 / \mathrm{k}_{\mathrm{r}}\left(\mathrm{k}_{\mathrm{r}}-\right.$ the Henry coefficient $\left.\mathrm{k}_{\mathrm{r}}=\mathrm{a}_{\mathrm{p}} / \mathrm{C}_{\mathrm{p}}\right)$.

The dependence of the value $\mathrm{T}$ on $\tau$ is expressed by a straight line coming out of the origin.

To determine the limiting phase of the adsorption process under kinetic conditions, we compare the graphical dependencies for various functions, i.e. If the adsorption kinetics is limited by external mass transfer, the dependence deviating from the direct one reflects the 
smooth transition of the process from external diffusion control to internal control, when the control over the extraction of the component from the aqueous medium passes to internal mass transfer. This is explained by the fact that when approaching equilibrium, the gradient of specific adsorption decreases, and, consequently, the rate of internal mass transfer, proportional to the gradient, also decreases.

\section{Results and their considerations}

During the experiment the primary information about the adsorption rate, i.e. the granule with adsorbate saturation rate, is represented by kinetic curves (Fig.1) characterizing the change in the adsorption value over time.

Studies have shown that a high adsorption rate observed for the studied activated carbons (AG-OV, CAU, CsAu, Purolate-Standard) at the initial stage. speed fires in the time interval. And the curve deviates from the classical form, which is due to the nonlinearity of the achievement of adsorption in the equilibrium period.

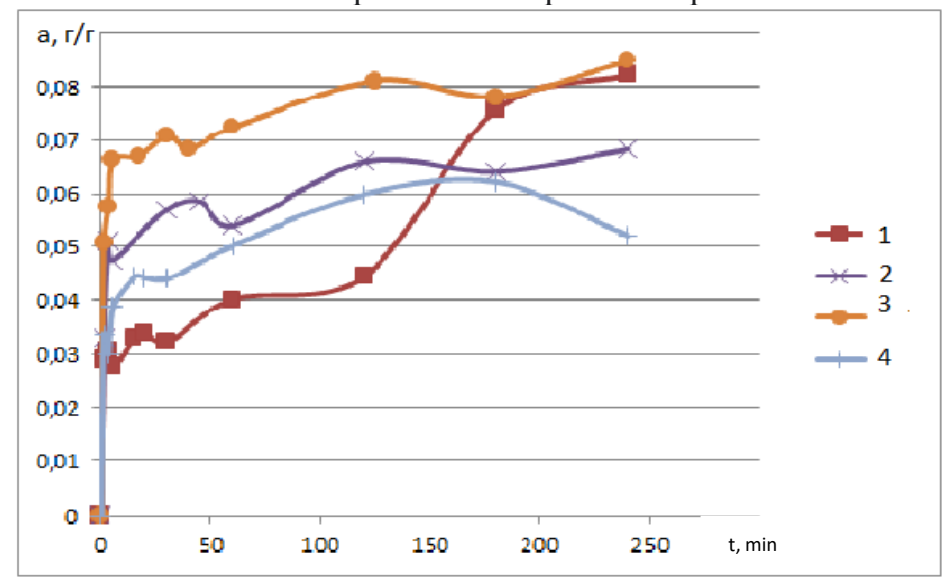

Fig. 1. Kinetic curves of trichloroethylene adsorption on active coals 1 AG-OV, 2 Purolate-Standard, $3 \mathrm{CAU}, 4 \mathrm{CsAu}$

The experimental data satisfactorily approximate the used pseudo-first-order and pseudo-second-order kinetic models (Fig. 2). 

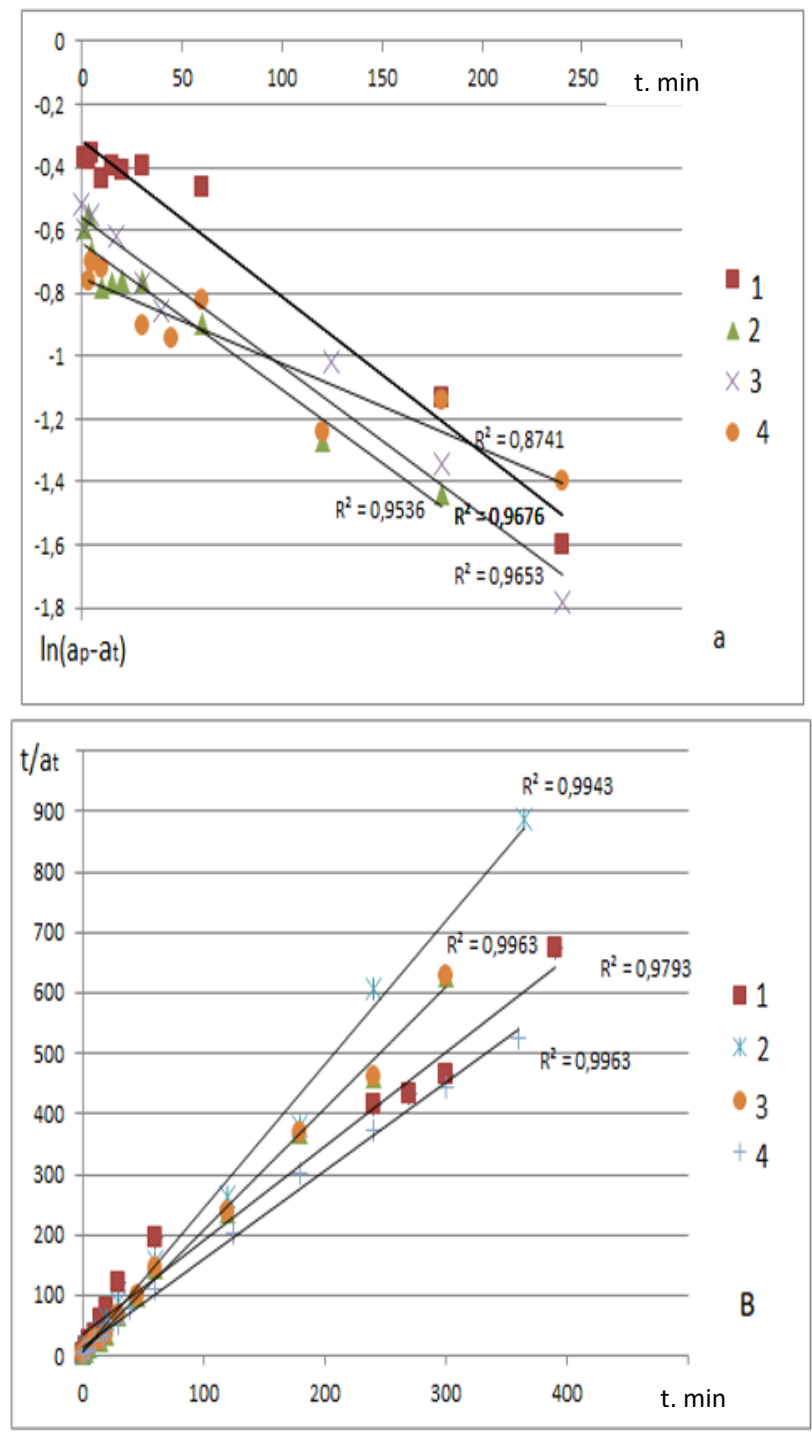

Fig. 2. The adsorption kinetics of trichloroethylene AU grades 1 AG-OV, 2 CAU, 3 PurolateStandard, $4 \mathrm{CsAu}$ description in the coordinates of pseudo-first-order (a) and pseudo-second-order (b)models

The kinetic curves are also analyzed in the coordinates $\gamma$ from $\tau$ (Fig. 3) and the dimensionless coefficient $T$ from $\tau$ (Fig.4) used in the R. M. Marutovsky method. The external mass transfer coefficients $\left(\beta_{\Pi}\right)$ are calculated by the tangent of the slope angle of the direct dimensionless coefficient T on $\tau$ dependence: $\beta$ CsAu $=0.0308 \mathrm{sec}^{-1}, \beta$ AG-OV-1 $=0.0282 \mathrm{sec}^{-1}, \beta \mathrm{KAU}=0.0411 \mathrm{sec}^{-1}, \beta$ Purolate-Standard $=0.2517 \mathrm{sec}^{-1}$. 

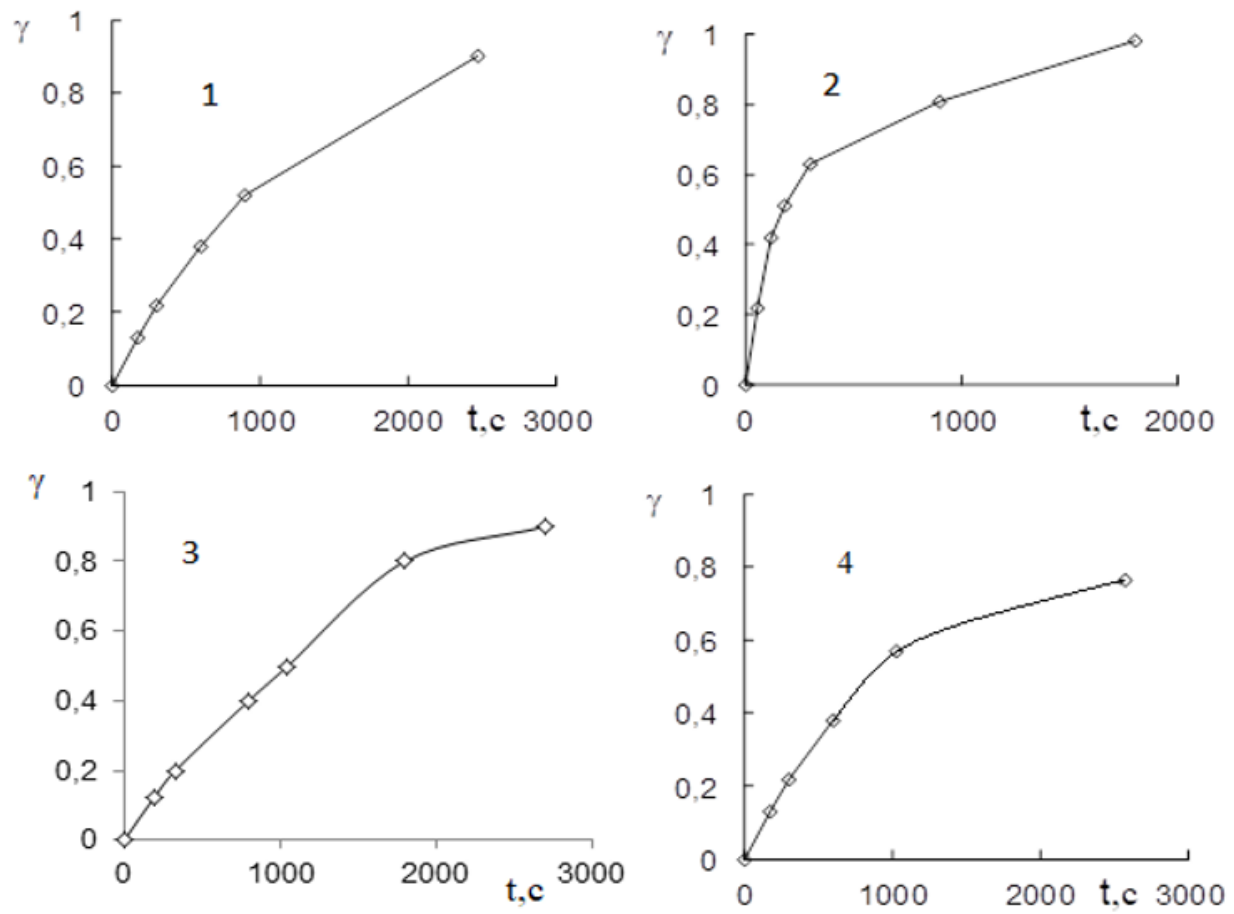

Fig. 3. Dependences of the adsorption equilibrium $\gamma$ achievement degree on the adsorption time $\tau$ : 1 AG-OV, 2 CAU, 3 Purolate-Standard, 4 CsAu
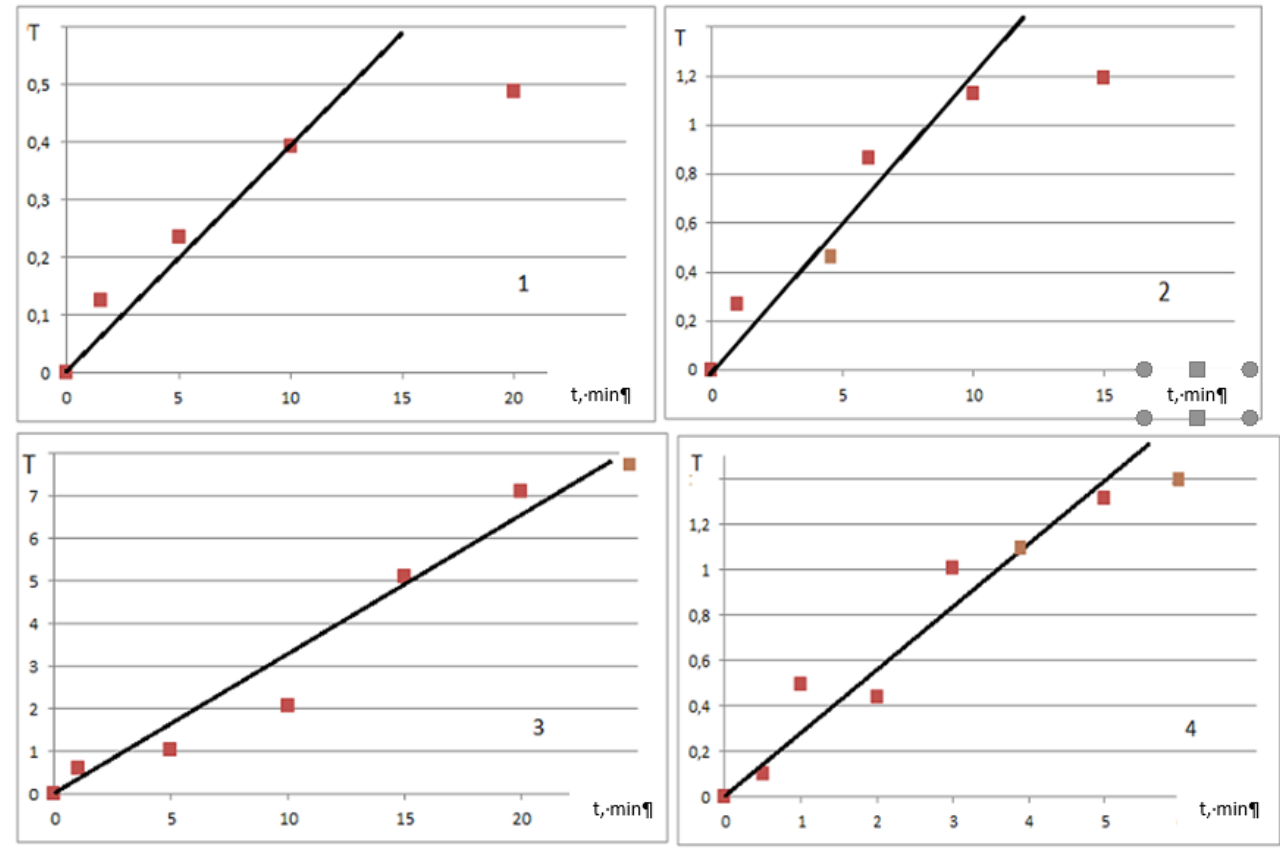

Fig. 4. Adsorption theoretical kinetic curves in the system of activated carbon are a trichloroethylene aqueous solution: 1 AG-OV, 2 CAU, 3 Purolate-Standard, 4 CsAu. 
The pseudo-first-order equation satisfactorily $\left(\mathrm{R}^{2}=0.87-0.96\right)$ describes the adsorption laws at the initial stages of the adsorption process (Fig. 2a) when the phenomenon of external diffusion has a significant influence on the process. The dissolved substance diffuses under the influence of the concentration gradient that occurs in the liquid filling the adsorption space.

The pseudo-second order equation describes the experiment with significant accuracy $(\mathrm{R} 2=0.97-0.99)$. The process is influenced by diffusion and is determined by the possibility of participating in the process adsorption of functional groups of the sorbent. And allows to use all the considered kinetic theories to describe the kinetics of trichlorethylene adsorption by the studied AC brands.

The kinetic dependences presented in Figure 3 allow us to find out the model of the active carbon granules structure. The initial section of the dependence curve of the achievement degree of adsorption equilibrium on time is rectilinear up to $\gamma=0.6-0.9$. High values of $\gamma$ on a straight section suggest that the used sorbents granules correspond to a quasi-homogeneous model so the sorbent is considered as a system formed by a disorderly interweaving of micro-and meso-pores in which it is impossible to distinguish between areas with only or predominantly meso-pores and areas containing only micro-pores.

The direct interval on the dependence $\mathrm{T}=\mathrm{f}(\tau)$ (Fig.4), based on the aspects of the theory of R. M. Marutovsky, gives reason to believe that the first 5-25 minutes of the extraction of trilene occurs due to the external movement of components along the grain sorbent, for a short period of contact the component occupies the pores available in size and the adsorption process approaches equilibrium, the rate at which adsorption proceeds inside the grain indicates that the external diffusion process determines the control stage of extraction [12], the deviation from the direct dependence demonstrates the predominance of internal diffusion, and the subsequent transfer or redistribution of trilene inside the activated carbon grain has little effect on the amount of adsorption, but is simply associated with the reorientation of molecules and the possible formation of a cluster structure.

For the coal-water solution of trilene system, the extraction process under kinetic conditions was studied and as a result, the external mass transfer coefficient $(\beta n)$ was obtained for various grades, it has its own value, for coal of the KsAU brand $\beta=0.0308 \mathrm{sec}$ 1, AG-OV-1 $\beta=0.0282 \mathrm{sec}-1$, KAU $\beta=0.0411 \mathrm{sec}-1$, Purolate-Standard $\beta=0.2517 \mathrm{sec}-1$. The coefficients of external mass transfer for active coals of the grades KsAU, AG-OV-1, KAU are close and have fairly high values for coal of the Purolat-Standard brand the value $\beta$ is an order of magnitude higher which is probably due to the most developed system of transport pores. The obtained data allow us to expect a high component extraction rate from the treated water when filtered through a fixed sorbent layer.

\section{Conclusion}

The conceptual approach chosen in the study of trichloroethylene adsorption of their "active carbon-aqueous solution component" system allowed us to analyze a number of existing theories that allow us to describe the kinetics under different extraction mechanisms; the diffusion model showed the presence of an external diffusion mass transfer that determines adsorption in a short period of time, but at the same time sufficient to saturate the sorbent grain with the extracted component; the "pseudo-first" and "pseudo-second" order theories confirmed the diffusion theory, and allowed us to assume a mixed-diffusion character adsorption under kinetic conditions. The values of the calculated mass transfer coefficient $(\beta \mathrm{n})$ are applicable for modeling and optimizing the extraction process under dynamic conditions, and the values allow us to expect a high recovery rate of the component during cleaning in stationary adsorbers. 


\section{References}

1. N. A. Egorova, A. A. Bukshuk, G. N. Krasovsky, Hygiene and Sanitation, 2, 18-23 (2013)

2. M. J. Nieuwenhuijsen, J. Grellier, R. Smith, N. Iszatt, J. Bennett, N. Best, Philosophical Transaction of The Royal Society A: Physical, Mathematical and Engineering Sciences, 367(1904), 4043-4076 (2009)

3. J. M. Wright, J. Schwartz, D. W. Dockery, Environmental Health Perspectives, 112(8), 920-925 (2004)

4. D. Baytak, A. Sofuoglu, F. Inal, S. C. Sofuoglu, Science of The Total Environment, 407(1), 286-296 (2008)

5. E. Y. Shkatova, O. G. Masaltseva, A.V. Oksuzyan, Toxic technical liquids, 32 (2013)

6. T. A. Krasnova, I. V. Timoshchuk, A. K. Gorelkina, Yu. S. Shulzhenko, Nauka i studia, 2, 77-79 (2018)

7. GOST R31951-2012 DRINKING WATER, Determination of the content of volatile organohalogen compounds by gas-liquid chromatography

8. L. K. Neuchudina, A. Ya. Golub, Yu. G. Yatluk, Butler's Messages, 27(14), 55-68 (2011)

9. S. Azizian, J. Coll. Inter. Sci., 276, 47-62 (2014)

10. S. A. Anurova, Water: Chemistry and Ecology, 6, 70-75 (2012)

11. D. P. Timofeev, Kinetics of adsorption, 252 (1962)

12. I. M. Fedotkin, A. M. Kohanovsky, I. G. Roda, R. M. Muratovski, Physical chemistry, 48(2), 473-475 (1994) 